\title{
CHARACTERIZATION OF SULFATE-REDUCING BACTERIA ISOLATED FROM SEWAGE DIGESTOR FLUIDS
}

\author{
ATSUKO UEKI, RYOZO AZUMA,* AND TSUNEJI SUTO** \\ Laboratory of Applied Microbiology, Faculty of Agriculture, \\ Yamagata University, Tsuruoka 997, Japan \\ *Hokkaido Branch Laboratory, National Institute of Animal Health, \\ Sapporo 061-01, Japan \\ **Nippon Veterinary \& Zootechnical College, Musashino, \\ Tokyo 180, Japan \\ (Received May 25, 1981)
}

\begin{abstract}
Sulfate-reducing bacteria isolated from sewage digestor fluids and other natural habitats were characterized by their morphological, physiological and chemical properties. Strains (A-1 and B-1) isolated from drains were identified as Desulfovibrio desulfricans. On the other hand, isolates (F241, 1111 and KOKU) from sewage digestor fluids did not fully coincide with any sulfate-reducing bacteria hitherto described in several features of carbon sources utilization and nutritional requirements. They were thought to be atypical $D$. desulfricans and were named $D$. desulfricans subsp. stercorivorus nov. subsp. The cellular fatty acid composition of the isolates was analyzed and used effectively for the identification thereof.
\end{abstract}

Sulfate-reducing bacteria in sewage digestors and other natural environments were enumerated and isolated by the anaerobic roll tube method $(1,2)$. The addition of supernatant of autoclaved sewage digestor fluids (SDF) to the medium remarkably increased viable counts of sulfate-reducers in the sewage digestor fluids, but not in the other habitats $(1,3)$. This physiological difference of sulfate-reducers according to their habitats is of interest as regards investigation from ecological and taxonomical viewpoints. Thus, in the previous report, nutritional requirements of the isolates were investigated (4). All the strains isolated from the sewage digestor fluids appeared to require biotin as necessary for growth, while the strains isolated from the drains did not. The strains of sulfate-reducers requiring biotin seem to be worth characterizing for placement in exact taxonomical positions. Thus, this paper describes the characterization and identification of these isolates. 


\section{MATERIALS AND METHODS}

Cultivation method and media. All the procedures for cultivation of sulfatereducers were carried out by the modified anaerobic roll tube method as described previously $(1,3)$. Medium $(\mathrm{S}-)(1)$, and Medium $(\mathrm{S}+)(1)$ which was supplemented with $10 \%(\mathrm{v} / \mathrm{v})$ of SDF, were prepared as described previously. Strains were maintained on slants of Medium $\left(\mathrm{S}_{-}\right)$) or Medium $(\mathrm{S}+)$, and various tests for characterization were performed by using liquid Medium $\left(\mathrm{S}_{-}\right)$or Medium $(\mathrm{S}+)$ according to the requirement for SDF of each strain. Cells for pigments detection and determination of DNA base composition were grown in modified liquid Medium $\left(\mathrm{S}-\right.$ ) or Medium $\left(\mathrm{S}+\right.$ ), both of which contained $2 \mathrm{~g}$ of $\mathrm{Na}_{2} \mathrm{SO}_{4}$ and $5 \mathrm{~g}$ of sodium lactate per liter. To examine utilization of various carbon sources, sodium lactate was replaced by each of the carbon sources, respectively in $0.5 \%(\mathrm{w} / \mathrm{v})$. Cells were inoculated into test media from slants by a platinum loop and the growth was measured by increase in the turbidity using medium with no carbon source as a control. Low- $\mathrm{FeSO}_{4}(4)$ medium supplemented with cysteine- $\mathrm{HCl} \cdot \mathrm{H}_{2} \mathrm{O}(0.5 \mathrm{~g} / l)$ as a reducing agent was used in these procedures unless otherwise stated. Growth in sulfate-free medium (5) was also examined by the anaerobic roll tube method by using cysteine- $\mathrm{HCl} \cdot \mathrm{H}_{2} \mathrm{O}$ as a reducing agent. Cultivation temperature was $30^{\circ}$ and mixed gas phase $\left(\mathrm{N}_{2} 95 \%\right.$ and $\left.\mathrm{CO}_{2} 5 \%\right)$ was used.

Pigments detection. Cells harvested in the early stationary phase were washed three times with $0.1 \mathrm{~m}$ phosphate buffer ( $\mathrm{pH} 7.0$ ) and suspended in the same buffer. Difference spectra of oxidation-reduction on whole cells were determined by using a Hitachi 356 double beam spectrophotometer or a Shimadzu UV-200 double beam spectrophotometer with $\mathrm{Na}_{2} \mathrm{~S}_{2} \mathrm{O}_{4}$ as a reducing agent. Desulfoviridin was detected by the method of Postgate (6).

Determination of DNA base composition. DNA was prepared by the method of SAITo and Miura (7). The guanine plus cytosine (GC) content of DNA was determined by measuring the thermal denaturation temperature ( $\mathrm{Tm}$ ) of the DNA (8). GC content of DNA of isolates was calculated from the Tm values of DNA of Desulfovibrio desulfricans (NCIB 8307) and Desulfovibrio vulgaris (NCIB 8303 ) used as standards. The GC contents of these DNA were quoted from Bergey's manual (9).

Electron microscopy. Cells harvested from a 2 days' culture on slants of Medium ( $\mathrm{S}-$ ) or Medium $(\mathrm{S}+)$ were used as specimens. Negative staining was observed with a Hitachi HU 12 electron microscope.

Measurements of organic acids. Organic acids were measured by gas-liquid chromatography (GLC) according to the method described previously (3).

Analysis of cellular fatty acid. Cellular fatty acid composition was analyzed by GLC on a glass capillary column coated with FFAP according to the method described previously (10). For all the strains, cells were grown under the same condition using modified liquid Medium $\left(\mathrm{S}+\right.$ ) which contained $2 \mathrm{~g}$ of $\mathrm{Na}_{2} \mathrm{SO}_{4}$ and $5 \mathrm{~g}$ 
of sodium lactate per liter, because the cellular fatty acid composition was affected to a greater or lesser extent by the condition of cultivation (10).

Similarity of cellular fatty acid composition. The similarity of the cellular fatty acid composition of each isolate with that of type strains was calculated by the formula of BERGAN ( $l l)$ as described by MIYAGAWA et al. (12) using the programmed computer.

Strains used. Six strains isolated from sewage digestors and drains $(I)$ were used. D. desulfricans (NCIB 8307), D. vulgaris (NCIB 8303) and Desulfovibrio salexigens (NCIB 8403) were used as standards.

\section{RESULTS}

\section{Cultivation of sulfate-reducers}

As shown in Fig. 1, sulfate-reducers were easily cultured on slants or in liquid media by the anaerobic roll tube method. In high- $\mathrm{FeSO}_{4}$ medium (4), much black precipitate was generated (Fig. 1). Thus, for easy handling, low-FeSO $\mathrm{F}_{4}$ medium was usually employed for the maintenance of strains and various tests.

\section{Characterization}

The isolates were characterized as given in Table 1.

Morphology. All the strains were gram-negative curved rods with a single polar flagellum. An electron micrograph of strain 1111 is shown in Fig. 2. When the cells of each strain were inoculated into low- $\mathrm{FeSO}_{4}$ semi-solid Medium

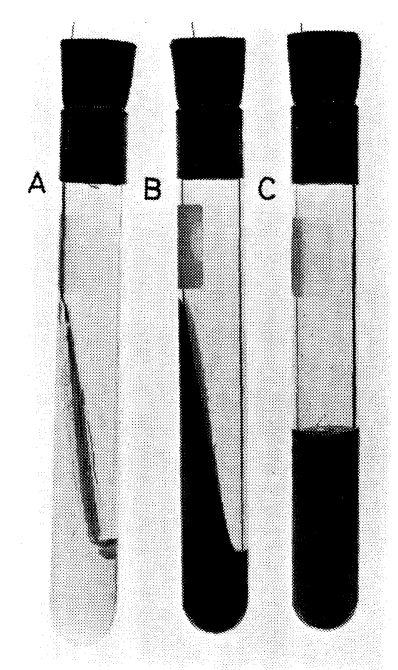

Fig. 1. Cultivation of sulfate-reducing bacteria (strain 1111) in the tubes with butyl rubber stoppers.

$\mathrm{A}$, on the slant of low- $-\mathrm{FeSO}_{4}$ Medium $(\mathrm{S}+)$; $\mathrm{B}$, on the slant of high- $\mathrm{FeSO}_{4}$ Medium $(\mathrm{S}+) ; \mathrm{C}$, in liquid high-FeSO ${ }_{+}$Medium $(\mathrm{S}+)$. 
Table 1. Characteristics of isolates of sulfate reducers.

\begin{tabular}{|c|c|c|c|c|c|c|}
\hline Strain & T206 & $\mathrm{F} 241$ & 1111 & KOKU & A-1 & B-1 \\
\hline 1. Gram stain & \multicolumn{6}{|c|}{ Negative $^{a}$} \\
\hline 2. Morphology & \multicolumn{6}{|c|}{ Curved rods } \\
\hline 3. Flagella & \multicolumn{6}{|c|}{ Single, polar } \\
\hline 4. Cytochrome & \multicolumn{6}{|c|}{$c_{3}$ (absorption max, 553, 523.5, and $\left.421 \mathrm{~nm}\right)$} \\
\hline 5. Desulfoviridin & \multicolumn{6}{|c|}{ Present } \\
\hline 6. Product from lactate & \multicolumn{6}{|c|}{ Acetic acid } \\
\hline 7. GC content & 54.0 & 54.7 & 54.0 & 54.5 & 55.3 & 55.7 \\
\hline \multicolumn{7}{|l|}{ 8. Growth in the presence of sulfate } \\
\hline Formate & + & + & + & + & + & + \\
\hline Malate & - & - & - & - & + & + \\
\hline Fumarate & - & + & + & + & + & + \\
\hline Ethanol & - & t. & + & + & + & + \\
\hline \multicolumn{7}{|l|}{ 9. Growth in the absence of sulfate } \\
\hline Pyruvate & + & + & + & + & + & t. \\
\hline Choline & - & - & - & - & + & + \\
\hline \multicolumn{7}{|l|}{ 10. Growth in the presence of $\mathrm{NaCl}$} \\
\hline $1.0 \%$ & + & t- & + & + & - & + \\
\hline $2.5 \%$ & - & + & + & + & - & + \\
\hline 11. Growth in Medium $(\mathrm{S}-)$ & - & $\ldots$ & - & - & + & + \\
\hline 12. Essential vitamin requirement & + & + & 4 & + & - & - \\
\hline 13. Essential SDF requirement & + & - & - & - & - & - \\
\hline 14. Source of $\operatorname{strain}^{b}$ & $\begin{array}{l}\text { Digestor } \\
\text { (A) }\end{array}$ & $\begin{array}{l}\text { Digestor } \\
\text { (A) }\end{array}$ & $\begin{array}{l}\text { Digestor } \\
\text { (B) }\end{array}$ & $\begin{array}{l}\text { Digestor } \\
\text { (D) }\end{array}$ & $\begin{array}{l}\text { Drain } \\
\text { (A) }\end{array}$ & $\begin{array}{c}\text { Drain } \\
\text { (B) }\end{array}$ \\
\hline
\end{tabular}

a Characteristics of 1-6 are common to all the strains.

$b$ See reference (3).

Fig. 2. Electron micrograph of strain 1111 (bar indicates $1 \mu \mathrm{m}$ ). 
$(\mathrm{S}-)$ or Medium $(\mathrm{S}+)$ which contained $0.2 \%(\mathrm{w} / \mathrm{v})$ agar, motility was also demonstrated because the medium became turbid all over.

Pigments. Desulfoviridin was detected in all the strains. Difference spectra of whole cells indicated the presence of $c$-type cytochrome with absorption maxima at $553,523.5$, and $421 \mathrm{~nm}$.

DNA base composition. The value of the GC content of DNA was $55.0 \pm 1$ in all the strains. This value was regarded as being equivalent to that of $D$. desulfricans $(55.3 \pm 1)(9)$.

Carbon sources utilization. Results of carbon sources utilization tests are shown in Table 1. In the presence of sulfate, malate supported the growth of strains A-1 and B-1 but not that of strains isolated from the sewage digestor fluids (F241, 1111, KOKU, and T206). Further, all the strains grew with lactate and pyruvate but not with glycerol, succinate, citrate, mannitol, inositol, glucose, aspartate, alanine, glycine, glutamate, or Casamino acids (Nissui) in the same condition. In the absence of sulfate, all the strains utilized pyruvate, while choline was utilized only by A-1 and B-1.

In the presence of $0.5 \%(\mathrm{w} / \mathrm{v}) \mathrm{NaCl}$, all the strains were able to grow, but not in $5 \%(\mathrm{w} / \mathrm{v}) \mathrm{NaCl}$. End product from lactate was acetate for all the strains.

Nutritional requirement. The nutritional requirement of the isolates has been described in a preceding paper in further detail (4). In short, the results were as follows. None of the strains isolated from the sewage digestor fluids could grow in Medium (S-). Three of them (F241, 1111 and KOKU) were able to grow in the medium containing $0.5 \%(\mathrm{w} / \mathrm{v})$ yeast extract even without SDF, but one strain (T206) still required SDF as necessary for growth. All these four strains required biotin as an essential vitamin and the growth of the former 3 strains was stimulated by $p$-aminobenzoic acid (PABA). In contrast, strains A-1 and B-1, isolates from the drains, could grow in Medium $(\mathrm{S}-)$, though their growth was accelerated by addition of PABA.

Cellular fatty acid composition. The cellular fatty acid composition of the isolates is presented in Table 2. As previously reported (10), Desulfovibrio species, with the exception of $D$. gigas, contain odd-numbered branched-chain saturated and unsaturated fatty acids as major acids. The presence of branched-chain unsaturated acids is an important characteristic of the cellular fatty acid composition of Desulfovibrio species other than D. gigas. The GLC analysis patterns of fatty acid methyl esters of the isolates were almost the same as those of $D$. desulfricans and D. salexigens.

The similarity value based on the GLC analysis between each isolate and each type strain was calculated. The value obtained with $D$. desulfricans was higher than that with the other two type strains used (D. vulgaris and D. salexigens) for all the strains. The value ranged between 0.99 (T206) and 0.93 (KOKU). 
Table 2. Cellular fatty acid composition of isolates of sulfate-reducers.

\begin{tabular}{|c|c|c|c|c|c|c|c|}
\hline \multirow{2}{*}{$\begin{array}{l}\text { Equivalent } \\
\text { chain length }\end{array}$} & \multirow{2}{*}{$\begin{array}{c}\text { Fatty }^{a} \\
\text { acids }\end{array}$} & \multicolumn{6}{|c|}{ Strains } \\
\hline & & T206 & $\mathrm{F} 241$ & 1111 & KOKU & A-1 & B-1 \\
\hline 14.02 & $14: 0$ & $3.7^{b}$ & 3.3 & 4.0 & 1.3 & 0.6 & 0.5 \\
\hline 14.28 & $14: 1$ & $\operatorname{Tr}$ & 0.6 & 0.5 & & $\operatorname{Tr}$ & $\operatorname{Tr}$ \\
\hline 14.58 & $i 15: 0$ & 24.6 & 18.4 & 17.0 & 26.3 & 19.7 & 18.8 \\
\hline 14.78 & $i 15: 1, a 15: 0$ & 2.1 & 2.0 & 1.2 & 1.6 & 1.1 & 1.5 \\
\hline 14.93 & $a 15: 1$ & & & 0.5 & & & \\
\hline 15.00 & $15: 0$ & & 3.2 & 3.0 & & $\operatorname{Tr}$ & $\operatorname{Tr}$ \\
\hline 15.30 & $15: 1$ & & $\operatorname{Tr}$ & $\operatorname{Tr}$ & & & \\
\hline 15.53 & $i 16: 0$ & & $\operatorname{Tr}$ & $\operatorname{Tr}$ & & $\operatorname{Tr}$ & $\operatorname{Tr}$ \\
\hline 15.70 & $i 16: 1$ & 0.8 & $\operatorname{Tr}$ & $\operatorname{Tr}$ & & & \\
\hline 15.81 & $i 16: 1$ & & & & & $\operatorname{Tr}$ & $\operatorname{Tr}$ \\
\hline 16.00 & $16: 0$ & 24.9 & 25.2 & 24.2 & 18.0 & 24.0 & 20.9 \\
\hline 16.24 & $16: 1$ & 3.6 & 3.9 & 5.6 & 1.2 & 8.7 & 6.2 \\
\hline 16.36 & $16: 1$ & 1.0 & 0.9 & 0.8 & 1.1 & $\operatorname{Tr}$ & $\operatorname{Tr}$ \\
\hline 16.53 & $i 17: 0$ & 9.9 & 7.2 & 9.1 & 21.0 & 12.4 & 15.1 \\
\hline 16.73 & $i 17: 1, a 17: 0$ & 23.1 & 20.7 & 24.6 & 22.1 & 23.8 & 28.5 \\
\hline 16.89 & $a 17: 1$ & & 0.6 & 0.6 & & & \\
\hline 16.98 & $17: 0$ & & 3.0 & 2.4 & & 0.5 & 0.5 \\
\hline 17.20 & $17: 1$ & & 3.0 & 1.7 & & & \\
\hline 17.71 & $i 18: 1$ & & 2.0 & 0.7 & 1.7 & & \\
\hline 17.98 & $18: 0$ & 2.8 & 1.4 & 1.0 & 3.0 & 5.8 & 3.0 \\
\hline 18.13 & $18: 1(49)$ & 0.8 & $\operatorname{Tr}$ & $\operatorname{Tr}$ & $\operatorname{Tr}$ & $\operatorname{Tr}$ & $\operatorname{Tr}$ \\
\hline 18.20 & $18: 1(\Delta 11)$ & 0.5 & 0.6 & 0.5 & 0.5 & 1.1 & 0.7 \\
\hline 18.53 & $i 19: 0$ & & 1.2 & 0.7 & 0.7 & & $\operatorname{Tr}$ \\
\hline 18.59 & $i 19: 1,3-\mathrm{OH} 14: 0$ & $\operatorname{Tr}$ & & & & $\operatorname{Tr}$ & 0.5 \\
\hline 18.90 & $a 19: 1$ & & 0.9 & 0.5 & 2.0 & & $\operatorname{Tr}$ \\
\hline 19.18 & 3-OHi15:0 & 1.3 & 0.5 & 0.6 & 0.6 & 0.6 & 0.7 \\
\hline 19.30 & $3-\mathrm{OH} a 15: 0$ & & $\operatorname{Tr}$ & & & & \\
\hline 20.18 & 3-OHi16: 0 & & & & & & $\operatorname{Tr}$ \\
\hline
\end{tabular}

a $i$, iso; a, anteiso; 3-OH, 3-hydroxy. The positions of double bonds were not determined except for $\mathrm{C}_{18: 1}$.

${ }_{b}$ Number refers to percentages to total acids: $\operatorname{Tr}=$ less than $0.5 \%$.

\section{DISCUSSION}

On the basis of the cell morphology (non-sporing, gram-negative curved rods with a single flagellum), the pigments (desulfoviridin and cytochrome $c_{3}$ ), and the cellular fatty acid composition, all the isolates are thought to be classifiable into the species of the genus Desulfovibrio. Following the scheme of classification of sulfate-reducers by Postgate and CAMPBell (13), various characteristics examined apparently indicate that strains $\mathrm{A}-1$ and $\mathrm{B}-1$ belong to $D$. desulfricans. On the other hand, identification of the other strains isolated from the sewage digestors faces some difficulties.

The pattern of the cellular fatty acid composition of these strains resembles that of $D$. desulfricans and $D$. salexigens, the highest similarity value being obtained 
with $D$. desulfricans for all the strains. The GC content of isolates is higher than that of $D$. salexigens and similar to that of $D$. desulfricans (9), $\mathrm{NaCl}$ not being required for their growth. Thus, the isolates from the sewage digestors are thought to also belong to $D$. desulfricans. Nevertheless, features of growth with various carbon sources in the presence or absence of sulfate and vitamin requirement distinguish these strains from the typical strains of $D$. desulfricans. In the scheme of Postgate and Campbell (13), the ability to grow with malate in the presence of sulfate and with pyruvate or choline in the absence of sulfate seems to be the key to the separation of $D$. desulfricans from other Desulfovibrio species. All the isolates could grow with pyruvate in the absence of sulfate, but neither malate nor choline supported the growth of the strains, with the exception of A-1 and B-1. These features do not agree with those of $D$. desulfricans described in the scheme.

SKYRING et al. (14) reported that the growth of isolates identified as D. desulfricans was not supported by choline in the absence of sulfate. In addition, utilization of malate by these isolates in the presence of sulfate was variable. Furthermore a sulfate-reducer isolated by BRYANT et al. (15) from a sewage digestor, of which the GC content was similar to that of $D$. vulgaris, grew well with pyruvate in the medium low in sulfate. These reports suggest that sulfate-reducers, of which the features of carbon sources utilization do not necessarily coincide with the above scheme, are present in natural environments.

Further, inability to grow in Medium ( $\mathbf{S}-$ ), which has usually been used for the cultivation of sulfate-reducers, and the requirement for a higher concentration of yeast extract seem to be characteristics specific to these strains. Essential vitamin requirement has not yet been reported for Desulfovibrio species hitherto described. SKYRING et al. (14) reported the presence of growth factors-requiring sulfatereducers identified as a new species of Desulfovibrio or variety of $D$. desulfricans. Several features of our isolates requiring vitamins or SDF, however, do not coincide with those of strains reported by them.

Under the above-mentioned circumstances, our isolates from the sewage digestors should be thought to be strains of $D$. desulfricans having characteristics physiologically different from typical members. Thus, we named the strains (F241, 1111 , and KOKU) isolated from sewage digestors $D$. desulfricans subsp. stercorivorus Ueki, Azuma and Suto nov. subsp. The type culture is $D$. desulfricans subsp. stercorivorus 1111 and is deposited with The Institute of Applied Microbiology, University of Tokyo.

The taxonomical position of T206, which is thought to also belong to $D$. desulfricans but the nutritional requirement of which is not clear, is yet to be clarified.

Besides the strains examined in this report, characterization of strain M2236 (I) which had been isolated from (C) digestor (1) was also attempted. This strain contained desulfoviridin and produced acetate from lactate. The pattern of cellular fatty acid composition coincided well with those of Desulfovibrio species except $D$. gigas. Nevertheless, the nutritional requirement seemed to be more complex than 
that of the other strains, and growth in any of the media used was too weak for obtaining sufficient cells for detection of cytochrome and determination of GC content. Thus, we could not identify this strain. The presence of these rather specific sulfate-reducers in sewage digestors is ecologically of interest.

The cellular fatty acid composition of sulfate-reducers usually has not been employed for their identification. However, the overall pattern of composition and the similarity value supplied useful information for the identification of sulfatereducers.

We wish to thank Dr. Y. Fujita, Ocean Research Institute, University of Tokyo, for the determination of type of cytochrome. We also thank Dr. Y. Ito, National Institute of Animal Health, for taking electron micrographs.

\section{REFERENCES}

1) A. Ueki, H. Minato, R. Azuma, and T. Suto, J. Gen. Appl. Microbiol., 26, 25 (1980).

2) R. E. Hungate, In Methods in Microbiology, 3B, ed. by J. R. Norris and D. W. Ribbons, Academic Press, London (1969), p. 117.

3) A. Ueki, E. Miyagawa, H. Minato, R. Azuma, and T. Suto, J. Gen. Appl. Microbiol., 24, 317 (1978).

4) A. Ueki and T. Suto, J. Gen. Appl. Microbiol., 27, 229 (1981).

5) J. R. Postgate, J. Bacteriol., 85, 1450 (1963).

6) J. R. Postgate, Nature (London), 183, 481 (1959).

7) H. Saito and K. Miura, Biochim. Biophys. Acta, 72, 619 (1963).

8) J. Marmur and P. Dotz, J. Mol. Biol., 5, 109 (1962).

9) R. E. Buchanan and N. E. Gibbons (ed.), Bergey's Manual of Determinative Bacteriology, 8th Ed., The Williams \& Wilkins Co., Baltimore (1974), p. 418.

10) A. Ueki and T. Suto, J. Gen. Appl. Microbiol., 25, 185 (1979).

11) T. Bergan, Bacteriol. Rev., 35, 379 (1972).

12) E. Miyagawa, R. Azuma, and T. Suto, J. Gen. Appl. Microbiol., 25, 41 (1979).

13) J. R. Postgate and L. L. Campbell, Bacteriol. Rev., 30, 732 (1966).

14) G. W. Skyring, H. E. Jones, and D. Goodchild, Can. J. Microbiol., 23, 1415 (1979).

15) M. P. Bryant, L. L. Campbell, C. A. Reddy, and M. R. Crabill, Appl. Environ. Microbiol., 33, 1162 (1977). 